\title{
Calculation and Analysis of Water Circulation Energetics in the Black Sea Coastal Regions
}

\author{
S.G. Demyshev, O.A. Dymova* \\ Marine Hydrophysical Institute, Russian Academy of Sciences, Sevastopol, Russian Federation \\ *e-mail: olgadym@yahoo.com
}

\begin{abstract}
The paper presents the analysis results of the kinetic and potential energy budget components calculated using eddy-resolving model of Marine Hydrophysical Institute. Numerical experiments were carried out with $1.6 \mathrm{~km}$ spatial resolution allowing for real atmospheric forcing in 2006. Temporalspatial variability of terms in energy budget equations was considered for the annual-averaged and seasonal-averaged time scales in the certain sea regions. The analysis of the maps of verticallyaveraged energetic components showed that, on average, over 2006 the most intensive energy exchange occurred along the western coast, in the southeast, near the Crimean and Anatolian coasts and in the RIM Current zone. It is revealed that the most energy-significant budget components are the buoyancy force in the northern and northeastern parts of the Black Sea, the wind force in its southern part, and the pressure and friction forces above the continental slope in the RIM Current zone. It was determined that the structure of currents in the northwestern shelf region in the cold period was determined by wind fields. In the warm period the generation of intensive eddies was observed due to an increase of available potential energy store. Formation of mesoscale eddies near the Crimean and the North Caucasus coasts occurred mainly in the spring-summer season as result of baroclinic instability. The basic factor conditioning mesoscale dynamics along the southern and the southeastern Black Sea coast in all the seasons and at a weak wind is the influence of the coastal obstacles upon the RIM Current periphery. The RIM Current region was the energy sink zone due to intensive horizontal dissipative and diffusion processes.
\end{abstract}

Keywords: the Black Sea, numerical modeling, kinetic energy, potential energy, mesoscale eddies.

DOI: 10.22449/1573-160X-2017-3-45-57

(C) 2017, S.G. Demyshev, O.A. Dymova

(C) 2017, Physical Oceanography

Introduction. With the development of the contact and remote World Ocean water probing methods the data on eddy structures with the spatial dimensions of about several kilometers and temporal variability with the scale from several days to several weeks became available. With regard to the local baroclinic Rossby radius of deformation $R_{d}$ these structures are divided into mesoscale quasigeostrophic eddies with the radius greater than $R_{d}$ (Rossby number Ro is much smaller than one for them) and sub-mesoscale ageostrophic eddies with the radius smaller than $R_{d}$ and Ro $\sim 1$ [1]. In the Black Sea coastal zone where $R_{d}$ makes up, on average $7.5 \mathrm{~km}$, eddies of both types are observed. The necessity of circulation investigation at the scale which is smaller than $10 \mathrm{~km}$ is dictated by several causes. Firstly, eddy structures of meso- and sub-mesoscale character can perform the exchange of mass, heat and salt between the coastal and deepwater parts and thus play an important role in the Black Sea hydrodynamics. Secondly, the outcomes of the works on MyOcean project, where the comparison of circulation numerical calculation results by three models with horizontal resolution from 5 to $8 \mathrm{~km}$ [4], demonstrated that horizontal resolution may have significant effect on the accuracy of hydrophysical characteristics forecast. Furthermore, such information on marine environment state is required for solving the problems of coastal ecosystems moni- 
toring. A great number of works created by S.F. Dotsenko [5] are devoted to the study and prediction of the consequences of natural catastrophic phenomena in the Azov-Black Sea region on the basis of numerical models.

There are several eddy-resolving models of the Black Sea dynamics. In the Institute of Numerical Mathematics of RAS and in P.P. Shirshov Institute of Oceanology of RAS high-resolution models [6, 7] (by which variability in the Black Sea and the Sea of Azov is studied) were developed. A number of diagnostic and prognostic experiments on the calculation of the Black Sea hydrophysical fields were carried out using POM [8], NEMO [9] and MHI [10] models taking into account real atmospheric effect and satellite information.

An effective instrument for assessing the role of various physical factors in the dynamics of currents is the analysis of the energy balance in the modeled system. In [11] different assessments of kinetic energy balance are used when choosing the criteria for completion of the adaptive calculations of hydrodynamic characteristics. Numerical analysis of energy transitions which take place during the study of the mechanisms of hydrophysical parameter anomaly generation in the Arctic Ocean was performed in [12]. In [13] the World Ocean energy cycle was calculated with the emphasis on the contribution of mesoscale eddies to the global circulation energy. Energy balances of semi-enclosed seas (including the Black Sea) are given in the paper [14], which shows that the buoyancy work is one of the main factors in the formation of the dynamics mesoscale features in semi-enclosed seas.

Energetics of the Black Sea climatic circulation (calculated at $5 \times 5 \mathrm{~km}$ grid) is represented in [15] where five energy-active zones located along the continental slope in the area of the North-Western Shelf (NWS), near the western part of the Anatolian coast, in the south-western part of the sea, in the central part of the Caucasian coast and near the eastern Crimea are determined. In [16], the components of the energy budget in 2006 are calculated with $1.6 \mathrm{~km}$ horizontal resolution on the basis of the finite difference equations of the kinetic (KE) and potential energy (PE) variations, taking into account the real atmospheric forcing. The analysis of averaged over the year and each season integral components of KE and PE budget was carried out. It is shown that during 2006 the variation of the Black Sea energy was determined mainly by the balance between the contributions made by the works of buoyancy, friction and wind forces.

The paper is devoted to the study of the Black Sea energetics and is the continuation of the analysis of numerical experiment [16] results. Spatial-temporal variability of vertically-integrated energy characteristics is considered. The purpose of this study was to analyze the most energy-significant components of potential and kinetic energy budget and to determine possible mechanisms of the formation and evolution of mesoscale eddies.

Numerical experiment. Assuming that $\langle\varphi\rangle^{H}=\int_{0}^{H} \varphi d z$, energy equations may be written down in the symbolic form in the following way [15]:

$$
\begin{aligned}
<E_{t}>^{H} & =\zeta_{t} E_{0}-g\left(\zeta^{2} / 2\right)_{t}-A d v_{\text {hor }}(P)-A d v_{\text {hor }}(E)+<\Pi \leftrightarrow E>^{H}+ \\
+\tau & \rightarrow E-\text { Diss }_{\text {bfr }}(E)-<\text { Diss }_{\text {ver }}(E)>^{H}-<\operatorname{Diss}_{\text {hor }}(E)>^{H},
\end{aligned}
$$


where $E_{t}$ is $\mathrm{KE}$ variation rate; $\zeta$ is a free surface elevation; $E_{0}=E(x, y, 0, t)$; $A d v_{\text {hor }}(P)=<(u P)_{x}+(v P)_{y}>^{H}$ is pressure work; $A d v_{\text {hor }}(E)=<(u E)_{x}+(v E)_{y}>^{H}$ is a KE advection; $\quad\left\langle\Pi \leftrightarrow E>^{H}=\left\langle g w \rho>^{H}\right.\right.$ is a buoyancy work; $\tau \rightarrow E=u_{0} \tau^{x}+v_{0} \tau^{y} \quad$ is $\quad$ a $\quad$ wind stress work; $\operatorname{Diss}_{\mathrm{bfr}}(E)=v_{V}\left(\left.\frac{\left(u^{2}\right)_{z}}{2}\right|_{z=H(x, y)}+\left.\frac{\left(v^{2}\right)_{z}}{2}\right|_{z=H(x, y)}\right)$ is KE variation due to bottom friction; $<\operatorname{Diss}_{\text {ver }}(E)>^{H}=v_{V}\left(u u_{z}+v v_{z}\right)_{z}$ is KE variation due to vertical internal friction; $<\operatorname{Diss}_{\text {hor }}(E)>^{H}=v_{H}\left[\left(\nabla^{2} u\right)^{2}+\left(\nabla^{2} v\right)^{2}\right]$ is KE variation due to horizontal friction (it includes internal horizontal friction and lateral friction).

$$
\begin{aligned}
& <\Pi_{t}>^{H}=-A d v_{\text {hor }}(\Pi)-<\Pi \leftrightarrow E>^{H}+<\operatorname{Diff}_{\text {hor }}(\Pi)>^{H}- \\
& -<\operatorname{Diff}_{\text {ver }}^{\kappa_{V}}(\Pi)>^{H}+<\operatorname{Diff}_{\text {ver }}^{\text {sur-bot }}(\Pi)>^{H}-<\operatorname{Diff}_{\text {ver }}^{\text {add }}(\Pi)>^{H},
\end{aligned}
$$

where $\Pi_{t}$ is PE variation rate; $A d v_{\text {hor }}(\Pi)=<(u \Pi)_{x}+(v \Pi)_{y}>^{H}$ is PE advection; $<\operatorname{Diff}_{\text {hor }}(\Pi)>^{H}=<-\kappa_{H}\left(\nabla^{4} \Pi-g z Q_{H}\right)>^{H}$ is PE variation due to inhomogeneity of horizontal turbulent diffusion; $<$ Diff ver $_{V}^{\kappa_{V}}(\Pi)>^{H}=<g \rho\left(\kappa_{V}\right)_{z}>^{H}$ is PE variation due to inhomogeneity of vertical turbulent diffusion coefficient by the depth; $<D i f f_{\text {ver }}^{\text {sur-bot }}(\Pi)>^{H}=g\left(\kappa_{v} \rho\right)_{z=0}-g\left(\kappa_{v} \rho\right)_{z=H(x, y)}$ is PE variation due to the difference between near-bottom and surface densities;

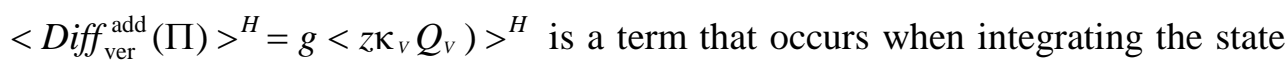
equation due to its nonlinear nature. The rest of the notations are universally accepted.

In contrast to [15], in the given study the calculations were carried out at $1.6 \mathrm{~km}$ grid, vertical turbulent processes were parameterized on the basis of Mellor-Yamada's turbulence closure model 2.5 [17], the wind, the heat fluxes, precipitation and evaporation obtained by the data of ALADIN [18] atmospheric model were taken into account. For specifying the hydrodynamic characteristics in the river mouths and straits climatic data [19] were used. For convenience of perception, the vertical integration sign $<>{ }^{H}$ is omitted hereinafter in the text.

Analysis of the results. Spatial distribution of certain terms (averaged over the year) of equations (1), (2) is given in Fig. 1. KE advection at the annual average scale was characterized by the values which were close to zero. They were small in comparison with the values of other terms. It is obvious from Fig. 1, $a$ that the maximum and the minimum values of pressure work are observed between 200 $900 \mathrm{~m}$ isobaths in the western part of the sea and near the coast of Turkey. In the same areas over the continental slope the greatest annual average velocity values 
were revealed in the core of the Rim Current. They lead to the increase of advective derivative value and, accordingly, to the intensification of pressure work. In the Batumi anticyclone zone mutually compensating areas of $A d v_{\text {hor }}(P)$ value are located, therefore, the total average annual contribution of the pressure work to the $\mathrm{KE}$ variation is insignificant in this region. Average annual distribution of buoyancy work is represented in Fig. 1, $b$. Buoyancy work depends on vertical velocity and density: $\Pi \leftrightarrow E=g w \rho$. A comparison with vertical velocity maps revealed that in the abyssal part (except for the southeastern part of the sea) the areas of positive and negative values of $\Pi \leftrightarrow E$ correspond to the zones of water level subsidence and rise, which are determined by vertical velocity sign. Positive values of $\Pi \leftrightarrow E$ prevail at the NWS (North-Western Shelf), correlation with the spatial distribution of vertical velocity is not indicated at that. Therefore, the buoyancy work at the NWS was mainly due to the density field which was determined by the heat fluxes, precipitation and evaporation on the sea surface and by freshwater river inflows. A transition of available potential energy (APE) to the KE in this region takes, on average over year, and thus the smothering of isopycnic surfaces took place. Thus, during the period under study the processes of cooling and winter convection in the NWS region were more energy-significant in comparison with the spring - summer warming of the waters, and the formation of mesoscale eddies, according to the authors, occurred against the background of barotropization of currents. However, this conclusion is just an assumption as it is difficult to assess the barotropic and baroclinic components of kinetic energy (as, for example, in [20]) on the basis of our approach.

On average over year KE increased due to the influx from the wind: the greatest contribution was recorded in the southwestern part of the sea and near the eastern part of the Anatolian coast (Fig. 1, c). Such distribution is due to the field of wind stress. The analysis of wind field revealed that in 2006 the strongest and the most repeatable winds had the northeastern direction with the maximum velocity values near the western coast. Negative values of wind stress work near the western part of the Anatolian coast (Fig. 1, c) mean that the wind and the currents have the opposite directions at the surface: the RIM Current is directed to the northeast and wind stress vector is directed mainly to the southwest. Due to this fact, the processes of shear instability are developing. They are one of the mechanisms of mesoscale eddy formation [21]. The analysis of maps of instantaneous currents and wind fields showed that in the given region eddy structures are formed between the RIM Current and the shore under weak winds as a result of the current running on the coastal obstacles. At the strong winds eddies were not observed. Thus, near the western part of the Anatolian coast mean annual wind influence on the circulation structure turned out to be less energy-significant than the impact of the coastline orographic features. 

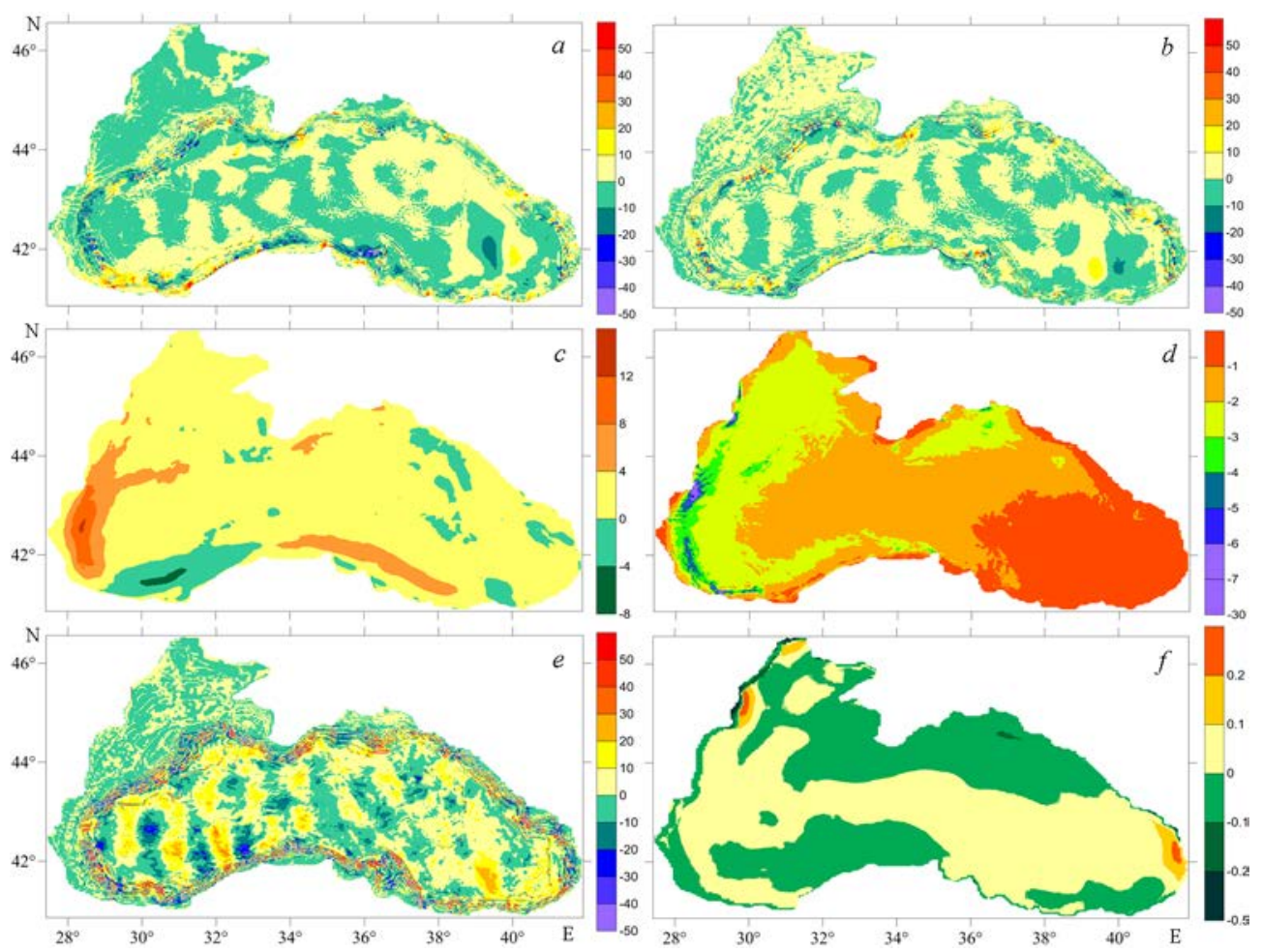

Fig. 1. Summands (erg/ $\left.\mathrm{cm}^{2}\right)$ in the equations (1), (2) averaged over the year: $a-A d v$ hor $(P) ; b-$ $\Pi \leftrightarrow E ; c-\tau \rightarrow E ; d-\operatorname{DisS}_{\text {ver }}(E) ; e-A d \nu_{\text {hor }}(\Pi) ; f-\operatorname{Diff}_{\text {ver }}^{\text {sur }}(\Pi)$

Significant KE losses due to vertical friction were recorded in the area of the southeastern coast of the Crimea and in the western part of the Black Sea with the maximum values near the coasts of Romania and Bulgaria (Fig. 1, $d$ ). This is explained by the intensification of mixing and vertical exchange processes in the zones where the strongest and the most frequently repeated winds were recorded. When calculating $\operatorname{Diss}_{\mathrm{ver}}(E)$, wind stress is directly taken into account as boundary condition not only in motion equations but also when calculating vertical exchange coefficients using Mellor - Yamada parameterization [17]. Therefore, wind strengthening leads to the increase of vertical velocity gradient, vertical turbulent exchange coefficients and, as a consequence, to larger in modulus Diss ver $(E)$ values. The most intensive KE sink due to horizontal dissipation occurs in the RIM Current. As the coefficients of horizontal turbulent viscosity are constant, KE loss due to the friction depends solely on the value of horizontal velocity gradients, which have larger values in the RIM Current than in other regions of the sea. The main contribution to $\operatorname{Diss}_{\text {hor }}(E)$ value was made by the upper model horizons in the winter period when the RIM Current is the most intensive. In summer, due to the weakening of the RIM Current and winds, numerous eddies of different scales are developing and energy losses due to horizontal friction decrease (in comparison with the cold season).

On average over 2006 the contributions of heat and salt fluxes at the sea surface and PE advection to the PE variation were the greatest. The largest in modulus values of the advective term in the equation (2) are localized above the continental slope (Fig. 1, $e$ ) where the velocity increase in the RIM Current core leads to an 
intensification of advective transport. In the abyssal part of the sea, to the west from $35^{\circ} \mathrm{E}$, an alternation of the zones of positive and negative values of $A d v_{\text {hor }}(\Pi)$ was observed. The same structure with the opposite sign was observed in the distribution of $A d v_{\text {hor }}(P)$ term in Fig. 1, $a$. These energy balance components are mutually compensating, their behavior is determined by vertical velocity. In [22] the existence of standing Rossby waves (their structure corresponds to the distribution of characteristics in Fig. 1, $a$ and Fig. 1, $e$ according to spatial-temporal scales) in the Black Sea is indicated.

In the spatial distribution of annually-averaged Diff ver $(\Pi)$ term (Fig. 1, $f$ ) a correspondence of total heat flux from the atmosphere to the annual average spatial distribution is determined: in those places where the heat flux is directed from the atmosphere to the sea (the water gets warm), Diff ver $(\Pi)$ term has a positive value. Thus, at the annual average scale the heat flux has the most significant effect on PE variation in the upper layer. Maximum Diff sur $(\Pi)$ values in the areas of the Danube and the Rioni River mouths are due to spring intensification of river runoff. With the increase of the difference between the surficial and near-bottom densities (i.e. with the increase of vertical density gradient value) the deviation of isopycnic surfaces from the mean "unperturbed" level also increases and, as a consequence, APE store rises. It is known from the literature that APE is a source of energy for mesoscale eddies [23]. Diff add $(\Pi)$ term is quite small in comparison with other components of PE balance, therefore, it is not taken into account further.

Thus, it can be seen from Fig. 1 that in 2006 the most intensive energy exchange occurred in the RIM Current area, near the western coast, in the southwestern part of the sea, near the Crimean and Anatolian coasts. The results of analysis of $\mathrm{KE}$ and $\mathrm{PE}$ budget components seasonal variability are represented below. The values of vertically integrated energy terms in the equations (1) and (2) were averaged over seasons. For each season the greatest contributions to the energy balance are assessed. We considered hydrologic seasons, i.e. three-month periods beginning on January 1, April 1, July 1 and October 1.
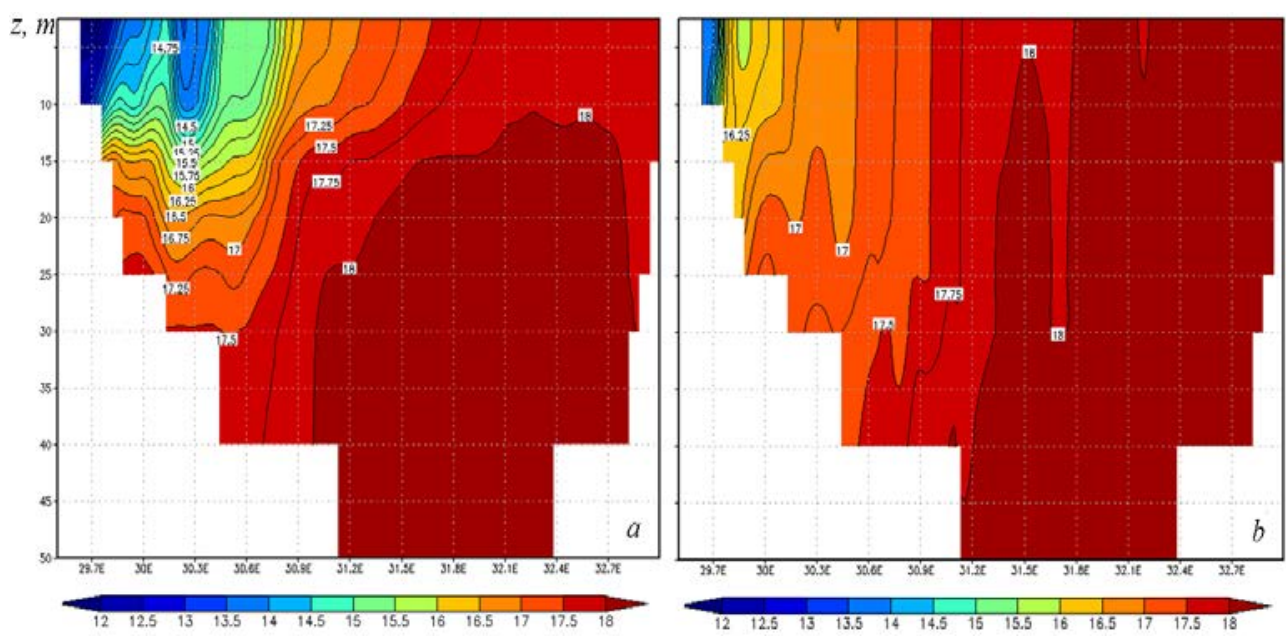

Fig. 2. Salinity field (\%o) at $45.2^{\circ} \mathrm{N}$ section: $a-22.05 .06, b-23.12 .06$ 
For the NWS and the western coast in the autumn-winter period the most significant KE balance components are the contribution of the wind and the losses due to vertical friction. These values characterize the restructuring of the current fields caused by storm winds (wind velocities were about $10 \mathrm{~m} / \mathrm{s}$ and higher) above the western part of the sea in the cold period. At this time jet currents directed mainly to the southwest were observed in the velocity field. In the western part of the sea $A d v_{\text {hor }}(P)$ contribution to the KE had the greatest values above the continental slope in all seasons of the year. PE variability in the NWS area is the most intensive in spring and summer due to river runoff intensification. Salinity field maps at the section corresponding to the latitude of the Danube mouth for cold and warm seasons are represented in Fig. 2. It can be seen that in spring the inflow of river waters results in the curving of isohalines, while in winter they are practically vertical. Thus, PE rises due to the increase of the difference between surficial and near-bottom densities. Deviation of isopycnic surfaces from the unperturbed level increases at that and it leads to the growth of APE store.

Seasonal variability of $\tau \rightarrow E$ and $D i s S_{\text {ver }}(E)$ terms near the Crimean coast is determined by the same factor as at the western coast: prescribed fields of wind stress. This means that in autumn-winter period the contribution from wind and the loss due to friction are the most significant components of energy balance and the currents are mainly of jet-like character. In all seasons of the year $A d v_{\text {hor }}(E)$ and $A d v_{\text {hor }}(P)$ mutually compensating zones are observed near the southeastern coast of the Crimea. As a result, the buoyancy work (Fig. 3) (the value of which is determined by the vertical velocity sign) becomes the dominant value in the KE balance. This value is positive most of the time, that is, the potential energy goes into the kinetic energy. In the absence of strong winds, this process is completed by the formation of short-lived mesoscale eddies in the velocity field.

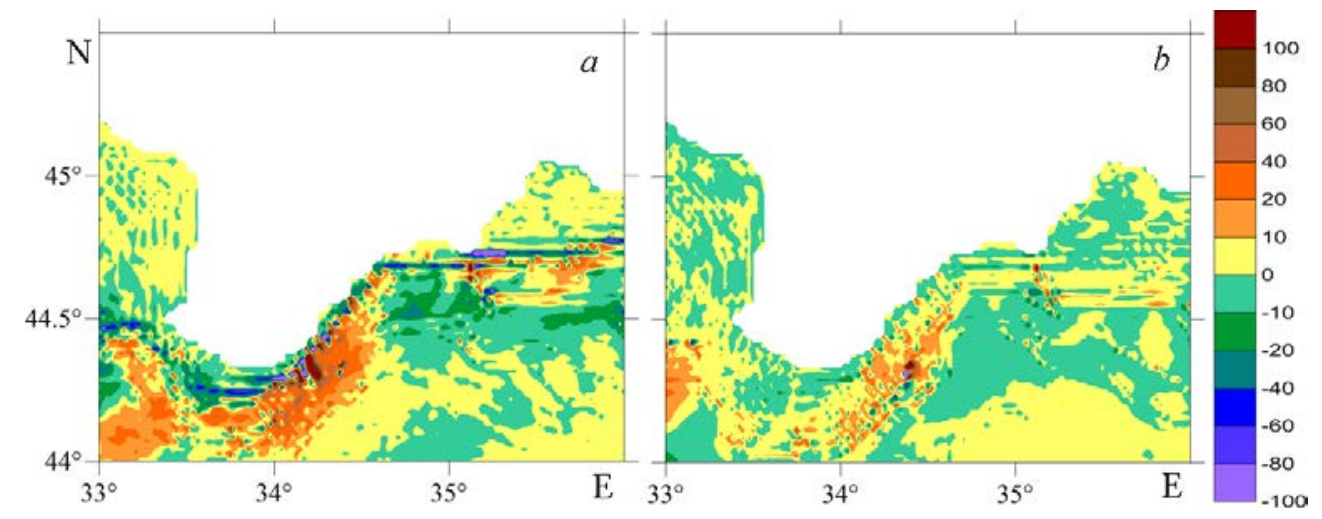

Fig. 3. The buoyancy work (erg/ $\mathrm{cm}^{2}$ ) averaged over a season: a - in winter, b - in summer

In a cold season in PE balance prevails Diff ${ }_{\text {ver }}^{{ }^{k_{V}}}(\Pi)$ term (its value reaches the maximum in the Karkinit Bay). The mechanism of Diff ${ }_{v e r}^{\kappa_{v}}(\Pi)$ variation is the following: with the depth increase the value of $\kappa_{V}$ vertical turbulent diffusion coefficient decreases. As it is calculated using Mellor - Yamada parameterization [17], where the wind stress is taken into account as a boundary condition at the surface, at strong and PHYSICAL OCEANOGRAPHY NO.3 (2017) 
prolonged winds in cold seasons vertical diffusive flux increases due to $\left(\kappa_{V}\right)_{z}$ vertical gradient increase. In spring PE increase is determined by high positive values of total diffusive flux near the coasts of the Crimea and the Caucasus. Its strengthening corresponds to the specified heat flux on the sea surface.

During the year the Anatolian coast is characterized by spatial-temporal inhomogeneity of KE budget components and relatively homogeneous distribution of PE budget components (except for $A d v_{\text {hor }}(\Pi)$ ). For reasons of presentation, the Turkish coast to the west from $34^{\circ} \mathrm{E}$ will be called the western part and the one to the east from $34^{\circ} \mathrm{E}$ - the eastern part. The feature of the western part is steep continental slope and of the eastern part - rather wide continental slope and indented coastline. In winter and autumn the pressure work decreases KE in the eastern part and increases it in the western one. In cold period of the year, when the water cools, its density and, consequently, the pressure increase. Pressure rise and intensification of currents above the narrow continental slope in the western part result in significant $A d v_{\text {hor }}(P)$ value increase. In all seasons the regions of the most intensive KE dissipation are recorded near the Turkish coast. The strengthening of dissipative processes is due to the RIM Current intensification above the narrow continental slope. When analyzing the distribution of $\tau \rightarrow E$ term (seasonallyaveraged) the following feature was found: in the western part of the Anatolian coast the wind stress work is negative and in the eastern one it is positive. The comparison of current maps at the upper computational horizon with the spatial distribution of the term (which characterizes the instantaneous work of wind force) revealed that under weak winds the zones of mesoscale eddy localization correspond to the areas of $\tau \rightarrow E$ negative values. In Fig. 4 the fields of currents and $\tau \rightarrow E$ for 19.03 .06 are given as an example. It should be pointed out that the value of wind stress above the region under investigation vary within $0.2-0.5 \mathrm{dyn} / \mathrm{cm}^{2}$ for the mentioned date. This corresponds to the near-water wind velocities within 1.5$2 \mathrm{~m} / \mathrm{s}$ range. Wind velocity was calculated according to the following formula: $\tau=\rho C_{d}\left|\vec{V}_{\text {wind }}\right|$ [24]. It can be seen from Fig. 4 that $\tau \rightarrow E$ term increases the kinetic energy of the RIM Current (red zones) and near the shore the zones of KE sink are formed (blue zones). The location of KE sink areas (Fig. 4, $b$ ) clearly coincides with the localization of mesoscale eddies in the velocity field (Fig. 4, b). $\tau \rightarrow E$ term is on the right side of expression (1) and is determined by the multiplication of vectors components of current velocity and wind stress $\left(u_{0} \tau^{x}+v_{0} \tau^{y}\right)$. If the value under investigation is negative, then the stream deceleration takes place and in the shelf zones behind-obstacle anticyclonic eddies [25] are formed. In the eastern part of the Anatolian coast shelf depth makes up, on average, $100 \mathrm{~m}$. Consequently, under weak wind shore orography has a significant influence on the currents and mesoscale eddies occur in relatively shallow areas behind the capes. When the wind gets stronger, the RIM Current gets closer to the shore, the area of KE sink zones decreases and in the coastal zone mesoscale eddies do not develop. Thus, the weakening of wind effect combined with the coastline orography effect may be the main prerequisites for the generation of mesoscale circulation features in the southern part of the Black Sea. On the basis of the foregoing we assume that 
in the areas where $\tau \rightarrow E$ term is negative KE of currents transforms into the eddy energy. However, this hypothesis requires further study.
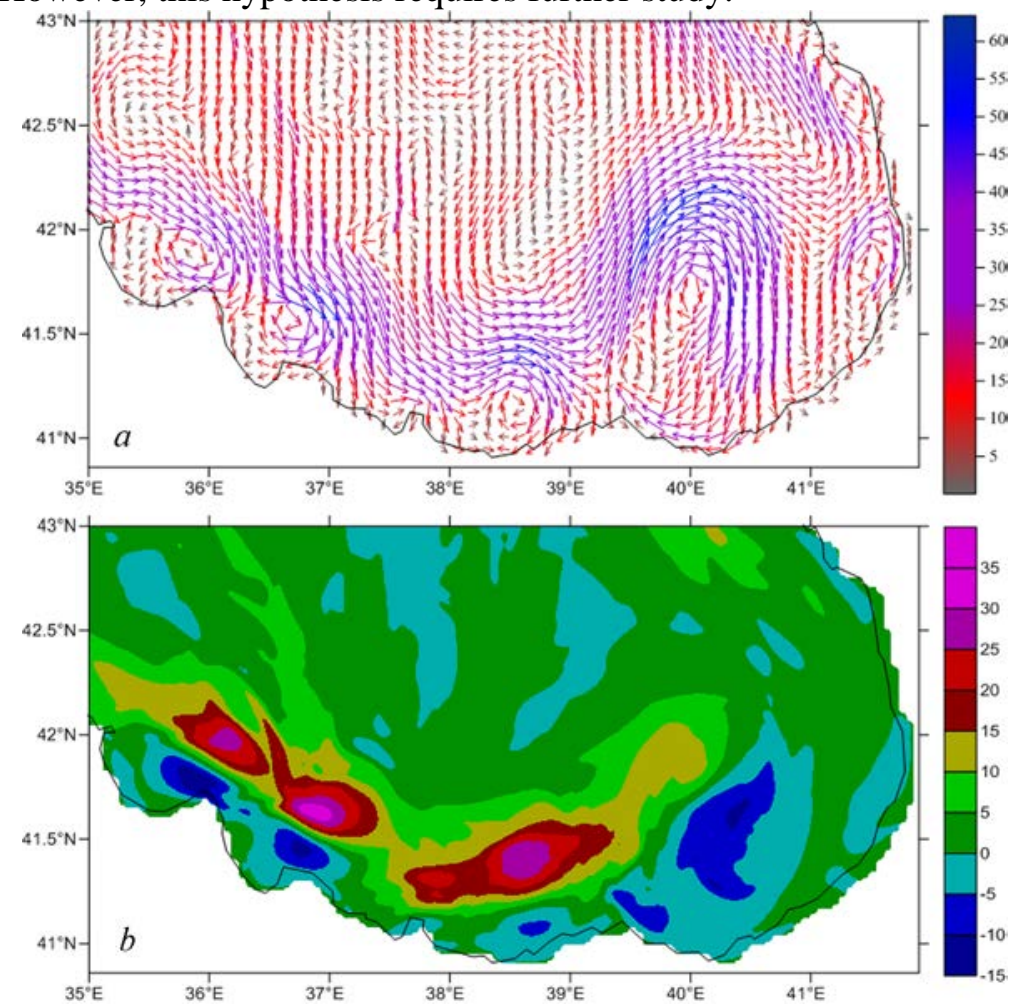

Fig. 4. The fields of velocity (cm/s) $(a)$ and $\tau \rightarrow E\left(\mathrm{erg} / \mathrm{s}^{2}\right)(b)$ for 19.03.06

Despite the absence of significant annual average contributions to the energy variation in the regions of the Batumi and Sevastopol anticyclones, in these areas adequate transport was carried out at the seasonal scale. Thus, from the spring mutually compensative $A d v_{\text {hor }}(E)$ and $A d v_{\text {hor }}(P)$ areas, corresponding to the location of anticyclones (Fig. $5 a, b$ ), begin to form. In those areas where the anicyclones contact with the main cyclonic gyre the highest velocities of currents are observed. Correspondingly, horizontal velocity gradients increase. This results in the increase of contribution of advective terms. In the Batumi anticyclone region $A d v_{\text {hor }}(\Pi)$ makes the main contribution to the PE variation (Fig. 5, c), which is due to high velocity gradients and great $\mathrm{PE}$ value in the abyssal part of the sea. In summer the RIM Current weakens and Sevastopol and Batumi anticyclones intensify. This (in energy-related aspects) leads to the area expansion of the zones in which the advective transport plays the main role in the energy exchange. In the warm period of the year $\Pi \leftrightarrow E$ value increase (Fig. $5, d$ ) is observed along the periphery of the Batumi anticyclone. Numerous small isoline features in the eastern part of the sea are manifested as a result of time-averaging. A comparison of instantaneous velocity fields and the buoyancy work fields revealed the correspondence of $\Pi \leftrightarrow E$ intensive variability zones (which is due to the density variation) to the zones of mesoscale eddy localization. This testifies to the increase of baroclinic instability processes. In the southeast, in the spring-summer period the contribution of $\operatorname{Diff} \mathrm{ver}_{\text {bot-sur }}^{\text {( }}(\Pi)$ term to PHYSICAL OCEANOGRAPHY NO.3 (2017) 
the PE variation increases due to river water inflow. APE store rises due to the increase of isopycnic surface deviation from the "unperturbed" level at that. The RIM Current intensification is characteristic of the autumn period (the velocity increase and stream width decrease). Sevastopol and Batumi anticyclones weaken, therefore the area of the zones corresponding to the greater values of advective terms in the expression (1) decreases. The cooling of waters and the increase of the upper quasi-homogeneous layer thickness result in PE rise but APE store decreases at that.

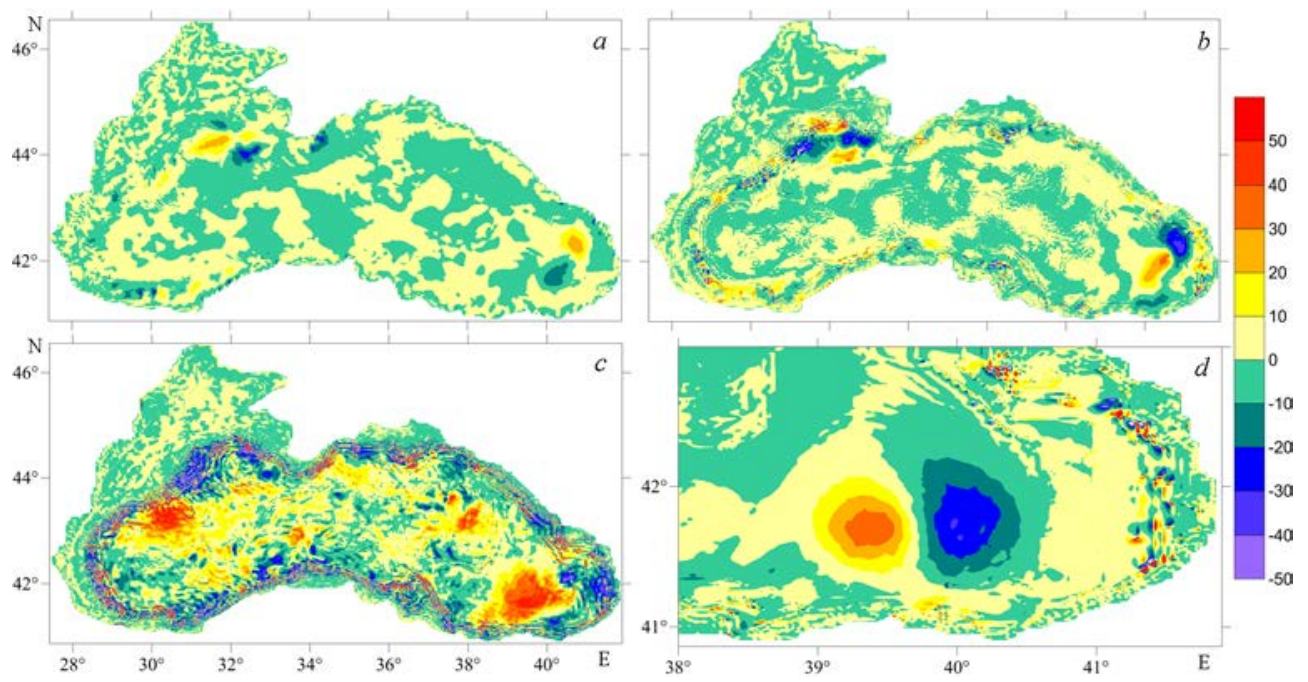

Fig. 5. Averaged over the spring advective fluxes $\left(\mathrm{erg} / \mathrm{cm}^{2}\right)$ : $a-\operatorname{Adv} v_{\text {hor }}(E), b-\operatorname{Ad} v_{\text {hor }}(P), c-$ $A d v_{\text {hor }}(\Pi) ; d-\Pi \leftrightarrow E$

The RIM Current is the zone where an intensive energy transformation takes place. The RIM Current core is localized above the continental slope. First of all, the RIM Current is the main area of energy sink due to horizontal dissipative and diffusive processes. In autumn-winter period (when the RIM Current is the most intensive) KE losses due to horizontal friction are commensurable with the value of advective contributions. The maximum KE sink was observed to the west from the Crimean Peninsula tip and near the western part of the Anatolian coast. The analysis of $\operatorname{Diss}_{\text {hor }}(E)$ value variation with the depth revealed the fact that in winter the main part of the energy got lost in the upper 75-meter layer. In spring and summer the friction work decreased by an order of magnitude. The coefficient of horizontal turbulent viscosity is constant, so the value of $\mathrm{KE}$ losses due to the friction is determined by the current velocity gradient only. PE decrease due to the horizontal diffusion is also the largest in the RIM Current zone, but Diff hor $(\Pi)$ value on the inter-seasonal scale varies slightly.

Conclusions. As a result of the numerical experiment, the components of the Black Sea kinetic and potential energy budget in 2006 were calculated. Temporalspatial variability of the main forces determining the features of circulation on annual-average and seasonal scales for different sea regions was considered. The analysis of the maps of energy budget vertically-averaged components showed that, on average over 2006 the most intensive energy exchange took place near the western coast 
and in the southeastern part of the Black Sea, near the Crimean and Anatolian coasts and in the RIM Current region.

In the cold period near the western coast and on the NWS stormy northeastern winds mainly determined the jet regime of currents, and KE variation was determined by the balance between wind contribution and a loss due to the vertical friction. In spring and summer, as a result of river runoff intensification the variations of isopycnic surfaces from the "unperturbed" level increased. This has resulted in APE store increase. The analysis of the buoyancy work in the NWS region revealed that in the absence of strong winds APE transferred from potential energy to the kinetic one and in this consequence mesoscale eddies were formed.

During the year near the Crimean coast the buoyancy work was the dominant component of energy balance. The value of this force was determined by vertical velocity sign at that. It is shown that the buoyancy work near the Crimean coast was mainly positive, i.e. the potential energy transferred to the kinetic one.

In autumn and winter near the Anatolian coast the pressure work made the main contribution to the KE variation. Great value of this force was determined by the advective transport intensification due to current velocities increase in the RIM Current core. The analysis of spatial distribution of wind stress work showed that in all seasons the zones of KE sink occurred by effects of coastline orography under condition of weak winds. Apparently, KE transformed into the energy of mesoscale eddies at that. When comparing the maps of wind stress work with the simulated velocity fields in the southern part of the Black Sea in 2006, spatial coincidence of the regions of mesoscale eddy localization with the KE sink zones was revealed.

The greatest contributions to the energy balance in the areas of Sevastopol and Batumi anticyclones were made by KE and PE advections. Spatial-temporal variability of these energy fluxes is due to the value of horizontal velocity gradients. They increased when current velocities rose in the areas where the anticyclones came into contact with the RIM Current. The RIM Current area was KE and PE sink zone due to intensive horizontal dissipative and diffusive processes, in winter the main part of KE got lost in the upper 75-meter layer.

Acknowledgements. The research was carried out within the framework of the State Order No. 0827-2014-0010 "Complex interdisciplinary research of oceanographic processes determining the functioning and evolution of the Black Sea and the Azov Sea ecosystems on the basis of modern methods for marine environment monitoring and grid technologies" ("Fundamental oceanography” code).

\section{REFERENCES}

1. Thomas, L.N., Tandon, A. and Mahadevan, A., 2008. Submesoscale Processes and Dynamics In: W.H Matthew and H. Hiroyasu, eds., 2013. Ocean Modeling in an Eddying Regime. Washington, D.C.: American Geophysical Union, pp. 17-38. doi:10.1029/177GM04

2. Karimova, S., 2012. Spiral Eddies in the Baltic, Black and Caspian Seas as Seen by Satellite Radar Data. Advances in Space Research, [e-journal] 50(8), pp. 1107-1124. doi:10.1016/j.asr.2011.10.027

3. Zatsepin, A.G., Baranov, V.I., Kondrashov, A.A., Korzh, A.O., Kremenetskiy, V.V., Ostrovkii, A.G. and Soloviev, D.M., 2011. Submesoscale Eddies at the Cauasus Black Sea Shelf and the Mechanisms of Their Generation. Oceanology, [e-journal] 51(4), pp. 554-567. doi:10.1134/S0001437011040205

4. Demyshev, S., Knysh, V., Korotaev, G., Kubryakov, A. and Mizyuk, A., 2010. The MyOcean Black Sea from a Scientific Point of View. Mercator Ocean Quarterly Newsletter, 39, pp. 1624. 
5. Dotsenko, S.F. and Ivanov, V.A., 2010. Prirodnye Katastrofy Azovo-Chernomorskogo Regiona [The Azov-Black Sea Region Nature Catastrophes]. [e-book] Sevastopol: ECOSIGidrofizika, 174 p. Available at: http://meteo.geofaq.ru/books/612759_D9E3D_docenko_s_f_ivanov_v_a_prirodnye_katastrofy_azovo_chernomors.pdf [Accessed 20 August 2016] (in Russian).

6. Zalesny, V.B., Gusev, A.V. and Moshonkin, S.N., 2013. Numerical Model of the Hydrodynamics of the Black Sea and the Sea of Azov with Variational Initialization of Temperature and Salinity. Izvestiya. Atmospheric and Ocean Physics, [e-journal] 49(6), pp. 642-658. doi:10.1134/S0001433813060133

7. Ibraev, R.A., 2001. A Study of the Sensitivity of the Model of the Black Sea Current Dynamics to the Surface Boundary Conditions. Oceanology, 5(41), pp. 615-621.

8. Kubryakov, A.I., 2004. Primenenie Tekhnologii Vlozhennykh Setok pri Sozdanii Sistemy Monitoringa Gidrofizicheskikh Poley v Pribrezhnykh Rayonakh Chernogo Morya [Application of Nested Grid Technology When Creating Hidrophysical Field Monitoring System in the Black Sea Coastal Areas]. In: V. A. Ivanov ed., 2004. Ekologicheskaya Bezopasnost Pribrezhnoy i Shel'fovoy Zon i Kompleksnoe Ispol'zovanie Resursov Shel'fa [Ecological Safety of Coastal and Shelf Zones and Complex Use of Shelf Resources]. Sevastopol: ECOSIGidrofizika. Iss. 11, pp. 31-50 (in Russian).

9. Mizyuk, A.I., Korotaev, G.K. and Ratner, Yu.B., 2014. Adaptatsiya Modeli NEMO dlya Vypolneniya Prognozov v Chernom More [NEMO Model Adaptation for Forecasting in the Black Sea]. In: Sovremennoe Sostoyanie i Perspektivy Narashchivaniya Morskogo Resursnogo Potentsiala Yuga Rossii [Current State and Prospects of Increasing the Marine Resource Potential of the South of Russian Federation]. Sevastopol, 15-18 September 2014. Sevastopol: ECOSI-Gidrofizika, pp. 181-184 (in Russian).

10. Demyshev, S.G., 2012. A Numerical Model of Online Forecasting Black Sea Currents Izvestiya. Atmospheric and Ocean Physics, 48(1), pp. 120-132. doi:10.1134/S0001433812010021

11. Sarkisyan, A.S., 1996. On Some Problems and Results of Ocean Modeling. Oceanology, 36(5), pp. 607-617.

12. Zalesny, V.B. and Ivchenko, V.O., 2010. Modeling the Global Circulation Response and the Regional Response of the Arctic Ocean to the External Forcing Anomalies. Oceanology, 50(6), pp. 829-840. doi:10.1134/S0001437010060020

13. Aiki, H., Zhai, X. and Greatbatch, R.J., 2016. Energetics of the Global Ocean: the Role of Mesoscale Eddies. In: The Indo-Pacific Climate Variability and Predictability. Vol. 7, ch. 4, pp. 109-134.

14. Cessi, P., Pinardi, N. and Lyubartsev, V., 2014. Energetics of Semienclosed Basins with TwoLayer Flows at the Strait. Journal of Physical Oceanography, [e-journal] 44(3), pp. 967-979. doi:10.1175/JPO-D-13-0129.1

15. Demyshev, S.G., 2004. Energy of the Black Sea Climatic Circulation. 1. Discrete Equations of the Time Rate of Change of Kinetic and Potential Energy. Meteorologiya i Gidrologiya, (9), pp. 65-80.

16. Demyshev, S.G. and Dymova, O.A., 2016. Analyzing Intraannual Variations in the Energy Characteristics of Circulation in the Black Sea. Izvestiya. Atmospheric and Ocean Physics, [ejournal] 52(4), pp. 386-393. doi:10.1134/S0001433816040046

17. Mellor, G.L. and Yamada, T., 1982. Development of a Turbulence Closure Model for Geophysical Fluid Problems. Rev. Geophys. Space Phys., [e-journal] 20(4), pp. 851-875. doi:10.1029/RG020i004p00851

18. Farda, A., Déué, M., Somot, S. Horányi, A., Spiridonov, V. and Toth, H., 2010. Model ALADIN as Regional Climate Model for Central and Eastern Europe. Studia Geophysica et Geodaetica, [e-journal] 54(2), pp. 313-332. doi:10.1007/s11200-010-0017-7

19. Altman, E.N. and Simonov, A.I. eds, 1991. Gidrometeorologiya i Gidrokhimiya Morey SSSR. T. IV. Chernoe more. Vyp. 1. Gidrometeorologicheskie usloviya [Hydrometeorology and Hydrochemistry of the USSR seas. Vol. IV. The Black Sea. Iss. 1. Hydrometeorologic Conditions]. Saint Petersburg: Gidrometeoizdat, 428 p. (in Russian). 
20. Robinson, A.R, Harrison, D.E., Mintz, Y. and Semtner, A.J., 1977. Eddies and the General Circulation of an Idealized Oceanic Gyre: a Wind and Thermally Driven Primitive Equation Numerical Experiment. Journal of Physical Oceanography, [e-journal] 7(2), pp. 182-207. doi:10.1175/1520-0485(1977)007<0182:EATGCO>2.0.CO;2

21. Zatsepin, A.G., Kremenetskiy, V.V., Stanichny, S.V. and Burdyugov, V.M., 2010. Basseynovaya Tsirkulyatsiya i Mezomasshtabnaya Dinamika Chernogo Morya pod Vetrovym Vozdeystviem [The Black Sea Basin-Scale Circulation and Mesoscale Dynamics under Wind Forcing]. In: Sovremennye Problemy Dinamiki Okeana i Atmosfery [Contemporary Problems of the Ocean and the Atmosphere Dynamics]. Moscow: TRIADA LTD, pp. 347-368 (in Russian).

22. Stanev, E. and Rachev, N., 1999. Numerical Study on the Planetary Rossby Modes in the Black Sea. Journal of Marine Systems, [e-journal] 21(1-4), pp. 283-306. http://dx.doi.org/10.1016/S0924-7963(99)00019-6

23. Korotaev, G.K., Kosnyrev, V.K. and Kuftarkov, Yu.M., 1977. O Dostupnoy Potentsial'noy Energii i Generatsii Mezomasshtabnykh Vikhrey v Okeane [On Available Potential Energy and Generation of Mesoscale Eddies in the Ocean]. Morskie Gidrofizicheskie Issledovaniya, 79(4), pp. 200-212 (in Russian).

24. Vol'tsinger, N.E. and Pyaskovskiy, R.V., 1968. Osnovnye Okeanologicheskie Zadachi Teorii Melkoy Vody [Basic Oceanographic Problems of Shallow Water Theory]. Saint Petersburg: Gidrometeoizdat, 300 p. (in Russian).

25. Elkin, D.N. and Zatsepin, A.G., 2013. Laboratory Investigation of the Mechanism of the Periodic Eddy Formation Behind Capes in a Coastal Sea. Oceanology, [e-journal] 53(1), pp. 24 35. doi:10.1134/S0001437012050062 